\title{
Genetic analysis of temperature-dependent transmission of mitochondrial DNA in Drosophila
}

\author{
ASAKO DOI, HIROMI SUZUKI \& ETSUKO T. MATSUURA* \\ Department of Biology, Ochanomizu University, Bunkyo-ku, Tokyo 112-8610, Japan
}

\begin{abstract}
In artificially induced mitochondrial DNA (mtDNA) heteroplasmy in Drosophila, the effects of chromosome substitution on temperature-dependent selection in mtDNA transmission were investigated. Using two strains of $D$. melanogaster, $b w ; e^{11}$ and $y ; b w ; s t$, which showed a different temperature dependency in mtDNA transmission, chromosomes were substituted reciprocally, and mtDNA of D. mauritiana was introduced into each newly constructed strain. For each heteroplasmy, the transmission of mtDNA was examined at $25^{\circ} \mathrm{C}$ and $19^{\circ} \mathrm{C}$. When either the second or the third chromosome of the $y ; b w ; s t$ strain was substituted with that of the $b w ; e^{11}$ strain, the temperaturedependent selection in mtDNA transmission was altered. The selection was not changed when either the second or the third chromosome of the $b w ; e^{11}$ strain was substituted with that of the $y ; b w ; s t$ strain, or even when both the second and the third chromosomes of the $b w ; e^{11}$ strain were substituted with those of the $y ; b w ; s t$ strain. These results suggest that the temperature-dependent selection in mtDNA transmission is co-operatively regulated by gene products that are encoded by the $\mathrm{X}$, second and third chromosomes.
\end{abstract}

Keywords: chromosome substitution, Drosophila, heteroplasmy, mitochondrial DNA, temperaturedependent selection, transmission.

\section{Introduction}

The maintenance and transmission of mitochondrial DNA (mtDNA) involves multiple processes of replication of mtDNA and mitochondria, and the partitioning of mitochondria to daughter cells. These processes are controlled by many genes in the nuclear genome that cooperate with mitochondrial genomes. Some nuclear genes involved in these processes have been reported in Saccharomyces cerevisiae (e.g. Foury, 1989; McConnell et al., 1990; Ling et al., 1995; Lockshon et al., 1995). Mitochondrial transcription factor A has recently been shown to be essential in the regulation of the copy number of mtDNA in the mouse (Larsson et al., 1998). However, no other genes that regulate the maintenance and transmission of mtDNA directly have been identified in multicellular organisms.

In higher animals and insects, the transmission of mtDNA has been investigated in heteroplasmy (Solignac et al., 1984; Rand \& Harrison, 1986; Laipis et al., 1988; Jenuth et al., 1996). In Drosophila, heteroplasmy

*Correspondence. E-mail: etmatsu@cc.ocha.ac.jp

(C) 1999 The Genetical Society of Great Britain. can be induced artificially by the transplantation of germ plasm (Matsuura et al., 1989) or egg cytoplasm (de Stordeur et al., 1989). Using these techniques, heteroplasmy has been established with intra- and interspecific combinations between mtDNA and the nuclear genome. In D. melanogaster and its closely related species, the transmission of mtDNA in such induced heteroplasmy has been selective, and selection has been shown to be dependent on the temperature at which heteroplasmic strains are maintained (Niki et al., 1989; Matsuura et al., 1991, 1993; Tsujimoto et al., 1991). Similar temperature-dependent selection has also been observed in heteroplasmy constructed with $D$. simulans and D. mauritiana (de Stordeur, 1997).

We have reported previously that the temperaturedependent modes of mtDNA transmission in heteroplasmic D. melanogaster possessing D. mauritiana mtDNA are different when two different strains of D. melanogaster are used (Matsuura et al., 1991; Tsujimoto et al., 1991). This difference has been found to be largely determined by the nuclear genome (Matsuura et al., 1997). In the present study, the effect of each major chromosome on temperature-dependent selection 
was examined in order to identify the nuclear genes responsible for the selective transmission of mtDNA.

\section{Materials and methods}

\section{Species and strains}

Two strains of D. melanogaster, $b w ; e^{11}$ and $y ; b w ; s t$, were used to examine the effect of each chromosome on the selective transmission of mtDNA. In our previous studies on mtDNA transmission in heteroplasmy, mtDNA of D. mauritiana (g20) introduced into these two strains was transmitted differently depending on the temperature (Matsuura et al., 1991; Tsujimoto et al., 1991). The entire nuclear genomes of the two strains have been shown to have different effects on temperature-dependent selection in mtDNA transmission (Matsuura et al., 1997). To assess the effect of each chromosome, chromosomes were substituted reciprocally between the two strains. A balancer strain, $S M 1 /$ $P m ; T M 3 / P r$, was used for the substitution. The g20 strain of D. mauritiana was used as a germ plasm donor to establish heteroplasmy as described below.

\section{Substitution of chromosomes}

Using the balancer strain, chromosome substitution was carried out according to standard procedures (Ashburner, 1989). For the second chromosome substitution, some modification was made to distinguish between the second chromosomes carrying $P m$ and $b w$ by using single flies for crosses in the $F_{2}$ and $F_{3}$ generations. Figure 1 shows the procedure for substituting the second chromosome of the $b w ; e^{11}$ strain with that of the $y ; b w ; s t$ strain. Similar crosses were made for substitutions of the other chromosomes.

When the second and third chromosomes of the $b w ; e^{11}$ strain were substituted with those of the $y$; $b w ; s t$ strain, the newly established strains were denoted B-y2 and $\mathrm{B}-\mathrm{y} 3$ respectively. These strains possessed mtDNA derived from the $b w ; e^{11}$ strain. For the reciprocal substitutions, the established strains were denoted as $\mathrm{Y}-\mathrm{b} 2$ and $\mathrm{Y}-\mathrm{b} 3$, possessing mtDNA derived from the $y ; b w ; s t$ strain. Reciprocal substitutions of both the second and the third chromosomes were also carried out. The established strains were similarly denoted as B$\mathrm{y} 2+\mathrm{y} 3$ and $\mathrm{Y}-\mathrm{b} 2+\mathrm{b} 3$, possessing mtDNA derived from the $b w ; e^{11}$ and $y ; b w ; s t$ strains respectively. The substitution of both the second and the third chromosomes resulted in the substitution of the $\mathrm{X}$ chromosome. That is, the $\mathrm{X}$ chromosome of the $b w ; e^{11}$ strain was substituted with that of the $y$; bw;st strain in the Y-b2+b3 strain, and vice versa.
The compositions of chromosomes and mtDNA in these constructed strains are shown in Fig. 2. The Y chromosome in each strain was derived from the strain used as male for a cross in the $\mathrm{F}_{2}$ generation. The fourth chromosome was mixed among the three strains, including the balancer. These strains possessed only one type of mtDNA on the basis of Southern hybridization (data not shown).

\section{Establishment and maintenance of the heteroplasmic line}

Using the experimental strains in which chromosomes were substituted as recipients and the g20 strain of D. mauritiana as a germ plasm donor, heteroplasmy was constructed by germ plasm transplantation, as described previously (Matsuura et al., 1989). Heteroplasmic lines were maintained at $25^{\circ} \mathrm{C}$ and $19^{\circ} \mathrm{C}$, and changes in the proportions of the two types of mtDNA were examined for 8-15 generations according to procedures described previously (Matsuura et al., 1989).

\section{Results}

\section{The second chromosome}

Using the B-y2 strain as a recipient, four heteroplasmic lines were established. Changes in the proportions of g20 mtDNA were examined at $25^{\circ} \mathrm{C}$ and $19^{\circ} \mathrm{C}$ for 12 and 13 generations respectively (Fig. 3a). The proportions of g20 mtDNA clearly increased in the four lines at $25^{\circ} \mathrm{C}$ but decreased at $19^{\circ} \mathrm{C}$, and g20 mtDNA was lost by the 13 th generation.

In the Y-b2 strain established by the reciprocal substitution, four heteroplasmic lines were examined for changes in the proportions of g20 mtDNA (Fig. 3b). At $25^{\circ} \mathrm{C}$, the proportions of $\mathrm{g} 20 \mathrm{mtDNA}$ increased by the 10 th generation. At $19^{\circ} \mathrm{C}$, however, the proportions slowly decreased. To determine whether this decrease was caused by the initial proportions of g20 mtDNA being relatively low, sublines were re-established from single females of one of the heteroplasmic lines at the sixth generation at $25^{\circ} \mathrm{C}$, in which the initial proportions of $\mathrm{g} 20$ mtDNA were $40-79 \%$. These sublines were maintained for five generations at $19^{\circ} \mathrm{C}$, and the proportions of g20 mtDNA clearly decreased (data not shown).

\section{The third chromosome}

Using the B-y3 and Y-b3 strains as recipients, three and four heteroplasmic lines were established respectively. Changes in the proportions of g20 mtDNA were examined at $25^{\circ} \mathrm{C}$ for 10 generations and at $19^{\circ} \mathrm{C}$ for eight generations. The results were essentially the same 


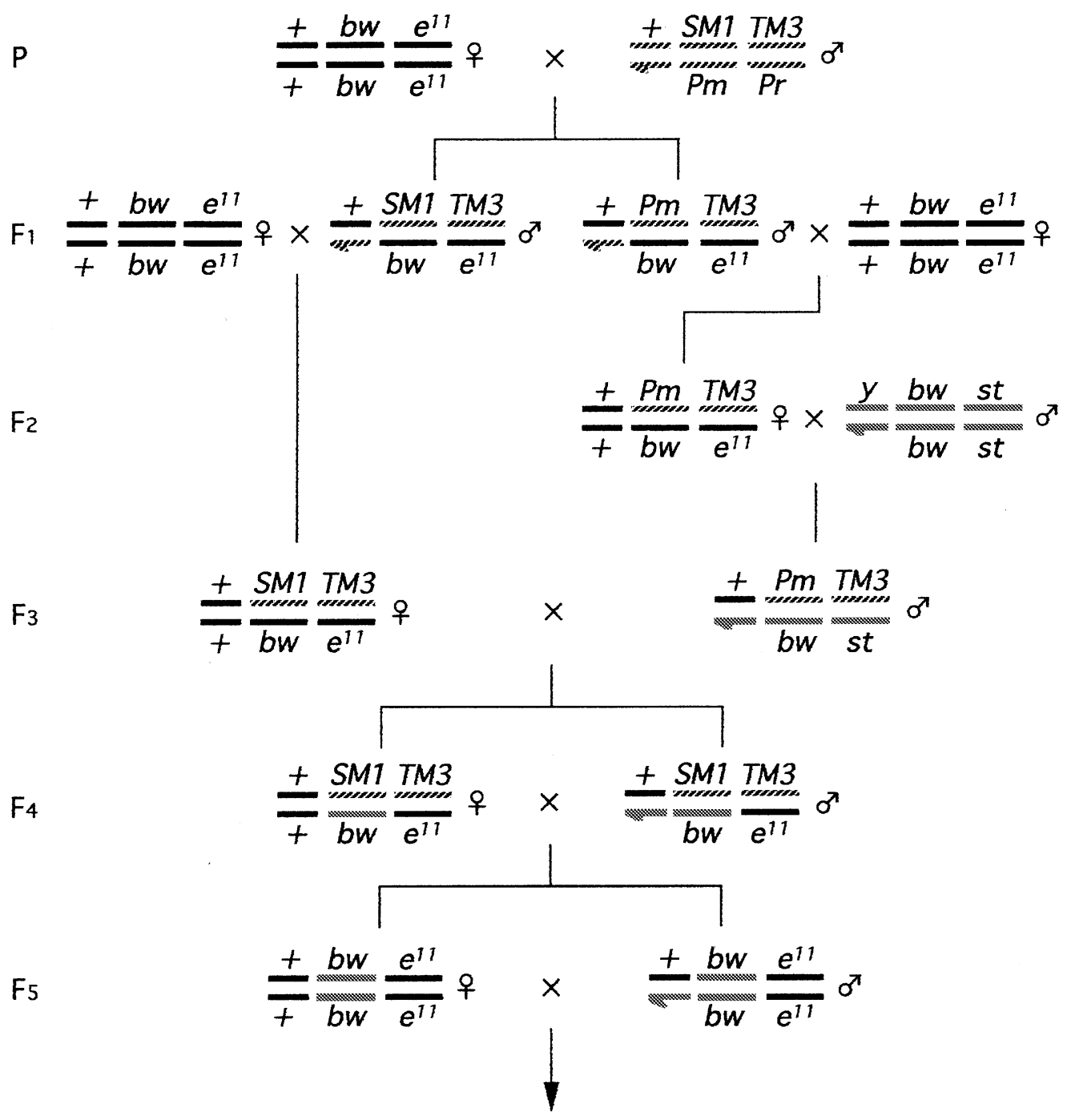

Fig. 1 Mating scheme for the substitution of the second chromosome of the $b w ; e^{11}$ strain with that of the $y$; $b w ; s t$ strain in Drosophila melanogaster. Black, dotted and hatched bars represent chromosomes derived from the $b w ; e^{11}$ strain, the $y ; b w ; s t$ strain and the balancer strain respectively.

as those for the second chromosome (data not shown). The proportions of g20 mtDNA increased at $25^{\circ} \mathrm{C}$ in two of the three lines for the B-y3 strain and in all four lines for the $\mathrm{Y}-\mathrm{b} 3$ strain. At $19^{\circ} \mathrm{C}$, the proportions clearly decreased in all lines examined.

\section{The second and third chromosomes}

Using the $\mathrm{Y}-\mathrm{b} 2+\mathrm{b} 3$ and $\mathrm{B}-\mathrm{y} 2+\mathrm{y} 3$ strains as recipients, three and four heteroplasmic lines were established respectively. Changes in the proportions of g20 mtDNA were examined for 15 generations at both temperatures. The results were similar to those described above (data not shown). The proportions of g20 mtDNA increased at $25^{\circ} \mathrm{C}$ and decreased at $19^{\circ} \mathrm{C}$ in all lines examined.

\section{Discussion}

In our previous study, the nuclear genomes of the $b w ; e^{11}$ and $y ; b w ; s t$ strains showed different effects on selection in mtDNA transmission in heteroplasmy (Matsuura et al., 1997). With the nuclear genome of the $b w ; e^{11}$ strain, the proportions of D. mauritiana (g20) mtDNA increased at $25^{\circ} \mathrm{C}$ and decreased at $19^{\circ} \mathrm{C}$. But with the nuclear genome of the $y ; b w ; s t$ strain, the proportions increased at both temperatures at different rates.

To determine which chromosome has the major effect on the selection, six kinds of chromosome constitution were constructed in the present study. As the effects of the nuclear genome on the selective transmission of mtDNA are large compared with the effects of the 


\begin{tabular}{|c|c|c|}
\hline & mtDNA $\left(b w ; e^{11}+\mathrm{g} 20\right)$ & mtDNA $(y ; b w ; s t+g 20)$ \\
\hline \hline $\begin{array}{c}\text { The second } \\
\text { chromosome } \\
\text { substitution }\end{array}$ & $\mathrm{B}-\mathrm{y} 2$ & $\mathrm{Y}-\mathrm{b} 2$ \\
\hline $\begin{array}{c}\text { The third } \\
\text { chromosome } \\
\text { substitution }\end{array}$ & $\mathrm{B}-\mathrm{y} 3$ & $\mathrm{Y}$ III \\
\hline $\begin{array}{c}\text { The second and third } \\
\text { chromosomes } \\
\text { substitution }\end{array}$ & $\mathrm{B}-\mathrm{y} 2+\mathrm{y} 3$ & $\mathrm{Y}-\mathrm{b} 2+\mathrm{b} 3$ \\
\hline
\end{tabular}

Fig. 2 Composition of the chromosomes for each strain of Drosophila melanogaster used as a recipient of germ plasm transplantation. Black and dotted bars represent chromosomes derived from the $b w ; e^{11}$ strain and the $y ; b w ; s t$ strain respectively.

mitochondrial genome that coexists with g20 mtDNA (Matsuura et al., 1997), the mitochondrial genome derived from either the $b w ; e^{11}$ strain or the $y ; b w ; s t$ strain was used for each chromosome constitution according to the substitution procedure. An X chromo- some substitution was also carried out by a similar procedure using a strain in which the entire nuclear genome of $b w ; e^{11}$ was substituted with that of $y ; b w ; s t$ (Matsuura et al., 1997), and heteroplasmy possessing D. mauritiana (g20) mtDNA was established. When (a)

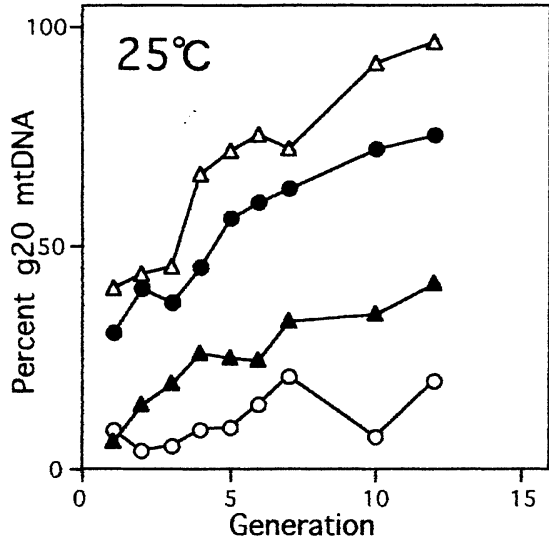

(b)

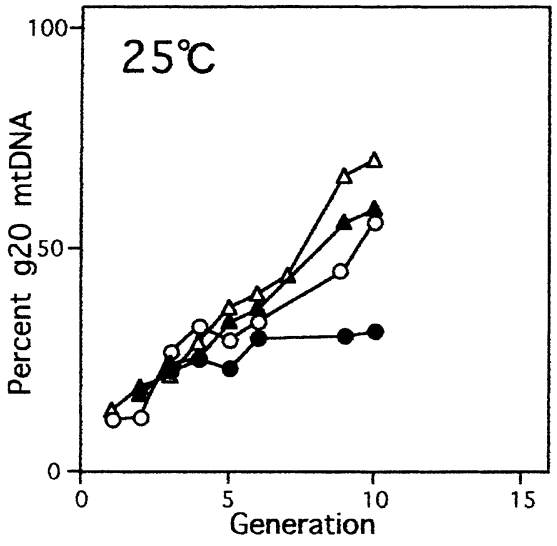

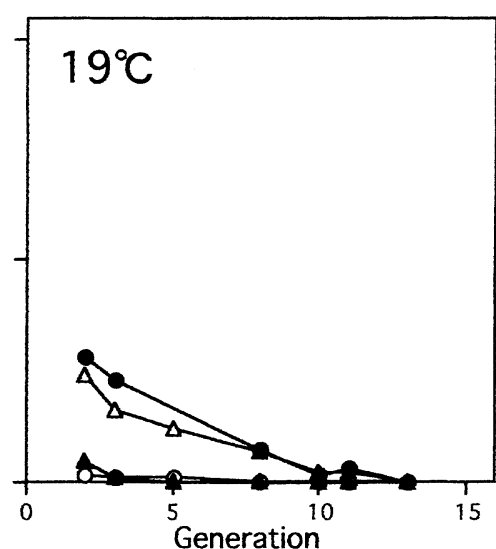

$19^{\circ} \mathrm{C}$

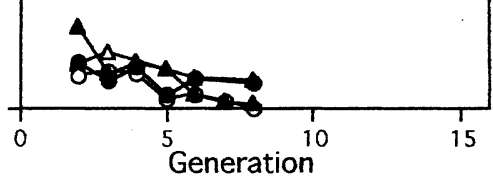

Fig. 3 Changes in the proportions of Drosophila mauritiana (g20) mtDNA introduced into the strains of D. melanogaster in which the second chromosome was substituted. (a) The B-y2 strain was used for the nuclear genome. (b) The Y-b2 strain was used for the nuclear genome.

(c) The Genetical Society of Great Britain, Heredity, 82, 555-560. 
almost the same constitutions of chromosomes were compared with two different combinations of mtDNA, the results from the heteroplasmy of $b w ; e^{11}$ and g20 mtDNA were essentially the same as those from the heteroplasmy of $y$; bw;st and g20 mtDNA (data not shown).

For the nuclear genomes in which major chromosomes were substituted, the proportions of g20 mtDNA increased at $25^{\circ} \mathrm{C}$ but decreased at $19^{\circ} \mathrm{C}$ when the chromosomes of the $y ; b w ; s t$ strain were substituted with those of the $b w ; e^{11}$ strain. However, the reciprocal substitutions did not change the direction of the selection at $19^{\circ} \mathrm{C}$. These results indicate that each of the three chromosomes of the $b w ; e^{11}$ strain can decrease the proportions of $\mathrm{g} 20 \mathrm{mtDNA}$ at $19^{\circ} \mathrm{C}$. From our previous results, the entire nuclear genome of the $y$; $b w ; s t$ strain could function to increase the proportions of g20 mtDNA at $19^{\circ} \mathrm{C}$ (Matsuura et al., 1997). This suggests that each of the three major chromosomes was involved in the temperature-dependent selection in mtDNA transmission, and that at least three genes cooperatively regulate the temperature-dependent process in mtDNA transmission.

To assess the effect of each chromosome substitution, the intensity of selection was estimated according to the method based on a model similar to genic selection in haploid organisms (Matsuura et al., 1993). Table 1 shows the averages of the selection coefficients for D. mauritiana $\mathrm{mtDNA}$ at $25^{\circ} \mathrm{C}$ and $19^{\circ} \mathrm{C}$ for each heteroplasmy. Comparing the values obtained in the present study with those for the $b w ; e^{11}$ and $y ; b w ; s t$ strains, possible differences in the effect of each chromosome substitution were suggested at $25^{\circ} \mathrm{C}$ as well as at $19^{\circ} \mathrm{C}$. It also appeared that the effects were larger when the $\mathrm{X}$ chromosomes were changed $(\mathrm{B}-\mathrm{y} 2+\mathrm{y} 3$ and $\mathrm{Y}-\mathrm{b} 2+\mathrm{b} 3)$. The tendency observed for the B-y2+y3 strain was confirmed in a different set of heteroplasmic

Table 1 Averages of selection coefficients for Drosophila mauritiana mtDNA in heteroplasmy

\begin{tabular}{llr}
\hline \multirow{2}{*}{$\begin{array}{l}\text { Strain used } \\
\text { as a recipient }\end{array}$} & \multicolumn{2}{c}{ Selection coefficient } \\
\cline { 2 - 3 }$b w ; e^{11} \dagger$ & $25^{\circ} \mathrm{C}$ & $19^{\circ} \mathrm{C}$ \\
$y ; b w ; s t \dagger$ & 0.329 & -0.334 \\
$\mathrm{~B}-\mathrm{y} 2$ & 0.476 & 0.275 \\
$\mathrm{Y}-\mathrm{b} 2$ & 0.182 & -0.318 \\
$\mathrm{~B}-\mathrm{y} 3$ & 0.250 & -0.237 \\
$\mathrm{Y}-\mathrm{b} 3$ & 0.283 & -0.211 \\
$\mathrm{~B}-\mathrm{y} 2+\mathrm{y3}$ & 0.330 & -0.266 \\
$\mathrm{Y}-\mathrm{b} 2+\mathrm{b} 3$ & 0.596 & -0.401 \\
\hline
\end{tabular}

$\dagger$ Matsuura et al. (1993).

(c) The Genetical Society of Great Britain, Heredity, 82, 555-560. strains established from another female (data not shown). These results suggest that the contribution of each chromosome to the temperature-dependent selection is not equal.

At present, the mechanism of the temperature-dependent transmission of mtDNA has not yet been clarified in Drosophila. From the present findings, two mechanisms could be proposed. First, a protein molecule composed of multiple subunits is critical for the temperature-dependent process. Substitution of any one of such subunits may affect the efficiency of the process. In this case, such a protein complex may be directly involved in the maintenance of mitochondrial genomes. For example, protein factors composed in a subunit structure are known to be necessary for the replication and/or transcription process of mtDNA (Shadel \& Clayton, 1997). Although the temperature dependency of such proteins has not been noted, one of these may show temperature-dependent activity. In D. melanogaster, DNA polymerase $\gamma$ is composed of two subunits (Olson et al., 1995). However, both have been found to be encoded on the second chromosome (Lewis et al., 1996; Wang et al., 1997). Secondly, multiple steps are involved in the temperature-dependent process, and many genes are responsible for the selection. Even for the normal activity of mitochondria, including both metabolic function and biogenesis, many proteins that are encoded in the nuclear genome are required. Some of these proteins may show temperaturedependent activity and may finally lead to the biased transmission of two types of mitochondria under certain conditions. In a recent report on mtDNA transmission in $D$. melanogaster, temperature-dependent selection was not detected in naturally occurring heteroplasmy for size variation in the $\mathrm{A}+\mathrm{T}$-rich region that contains the replication origin of mtDNA (Kann et al., 1998). The absence of temperature dependency in this case may possibly be explained by the two types of mtDNA being identical for the coding region, although the variable portion within the $\mathrm{A}+\mathrm{T}$-rich region was not identified.

In either case, the temperature-dependent selection should provide an opportunity for elucidating the molecular mechanisms of mtDNA transmission in multicellular organisms. Temperature-dependent selection controlled by the nuclear genome has not been reported in any organisms other than Drosophila. Similar phenomena, however, may be observed for other animal mtDNA when two types of mtDNA with different sequences can coexist within a cell. Genetic and molecular tools in Drosophila are useful for the future identification of nuclear genes involved in mtDNA transmission. Clarification of the selection in mtDNA transmission is essential in understanding the evolution of communication between the nuclear and mitochondrial genomes. 


\section{Acknowledgements}

The authors would like to express their sincere appreciation to Professor Sadao I. Chigusa, Ochanomizu University, for his encouragement and discussion during the course of this study. We would also like to thank Drs Yuzo Niki, Ibaraki University, and Teiichi Tanimura, Kyushu University, for their advice during the transplantation experiments. This work was supported in part by Grants-in-Aid for Scientific Research from the Ministry of Education, Science, Sports and Culture of Japan.

\section{References}

AShburner, M. 1989. Drosophila. A Laboratory Handbook. Cold Spring Harbor Laboratory Press, New York.

DE STORDEUR, E. 1997. Nonrandom partition of mitochondria in heteroplasmic Drosophila. Heredity, 79, 615-623.

DE STORDEUR, E., SOLIGNAC, M., MONNEROT, M. AND MOUNOLOU, J.-C. 1989. The generation of transplasmic Drosophila simulans by cytoplasmic injection: Effects of segregation and selection on the perpetuation of mitochondrial DNA heteroplasmy. Mol. Gen. Genet., 220, 127-132.

FOURY, F. 1989. Cloning and sequencing of the nuclear gene MIP1 encoding the catalytic subunit of the yeast mitochondrial DNA polymerase. J. Biol. Chem., 264, 20552-20560.

JENUTH, J. P., PETERSON, A. C., FU, K. AND SHOUbridGe, E. A. 1996. Random genetic drift in the female germline explains the rapid segregation of mammalian mitochondrial DNA. Nature Genet., 14, 146-151.

KANN, L. M., ROSENBlum, E. B. AND RAND, D. M. 1998. Aging, mating, and the evolution of mtDNA heteroplasmy in Drosophila melanogaster. Proc. Natl. Acad. Sci. U.S.A., 95, 2372-2377.

LAIPIS, P. J., VAN DE WALLE, M. J. AND HAUSWIRTH, W. W. 1988. Unequal partitioning of bovine mitochondrial genotypes among siblings. Proc. Natl. Acad. Sci. U.S.A., 85, 81078110.

LARSSON, N.-G., WANG, J., WILHELMSSON, H., OLDFORS, A., RUSTIN, P. AND LEWANDOSKI, M. ET AL. 1998. Mitochondrial transcription factor A is necessary for mtDNA maintenance and embryogenesis in mice. Nature Genet., 18, 231-236.

LEWIS, D. L., FARR, C. L., WANG, Y., LAGINA, A. T. III AND KAGUNI, L. S. 1996. Catalytic subunit of mitochondrial DNA polymerase from Drosophila embryos. J. Biol. Chem., 271, 23389-23394.
LING, F., MAKISHIMA, F., MORISHIMA, N. AND SHIBATA, T. 1995. A nuclear mutation defective in mitochondrial recombination in yeast. EMBO J., 14, 4090-4101.

LOCKSHON, D., ZWEIFEL, S. G., FREEMAN-COOK, L. L., LORIMER, H. E., BREWER, B. J. AND FANGMAN, W. L. 1995. A role for recombination junctions in the segregation of mitochondrial DNA in yeast. Cell, 81, 947-955.

McCONNELl, S. J., STEWART, L. C., TALIN, A. AND YAFFE, M. P. 1990. Temperature-sensitive yeast mutants defective in mitochondrial inheritance. J. Cell Biol., 111, 967-976.

MATSUURA, E. T., CHIGUSA, S. I. AND NIKI, Y. 1989. Induction of mitochondrial DNA heteroplasmy by intra- and interspecific transplantation of germ plasm in Drosophila. Genetics, 122, 663-667.

MATSUURA, E. T., NIKI, Y. AND CHIGUSA, S. I. 1991. Selective transmission of mitochondrial DNA in heteroplasmic lines for intra- and interspecific combinations in Drosophila melanogaster. Jap. J. Genet., 66, 197-207.

MATSUURA, E. T., NIKI, Y. AND CHIGUSA, S. I. 1993. Temperaturedependent selection in the transmission of mitochondrial DNA in Drosophila. Jap. J. Genet., 68, 127-135.

MATSUURA, E. T., TANAKA, Y. T. AND YAMAMOTO, N. 1997. Effects of the nuclear genome on selective transmission of mitochondrial DNA in Drosophila. Genes Genet. Syst., 72, 119-123.

NIKI, Y., ChigusA, S. I. AND MATSUURA, E. T. 1989. Complete replacement of mitochondrial DNA in Drosophila. Nature, 341, 551-552.

OLSON, M. W., WANG, Y., ELDER, R. H. AND KAGUNI, L. S. 1995. Subunit structure of mitochondrial DNA polymerase from Drosophila embryos. J. Biol. Chem., 270, 28932-28937.

RAND, D. M. AND HARRISON, R. G. 1986. Mitochondrial DNA transmission genetics in crickets. Genetics, 114, 955-970.

SHADEL, G. S. AND CLAYTON, D. A. 1997. Mitochondrial DNA maintenance in vertebrates. Ann. Rev. Biochem., 66, 409435.

SOLIGNAC, M., GÉNERMONT, J., MONNEROT, M. AND MOUNOLOU, J.-C. 1984. Genetics of mitochondria in Drosophila: mtDNA inheritance in heteroplasmic strains of D. mauritiana. Mol. Gen. Genet., 197, 183-188.

TSUJIMOTO, Y., NIKI, Y. AND MATSUURA, E. T. 1991. Further study on selective transmission of mitochondrial DNA in heteroplasmic lines of Drosophila melanogaster. Jap. J. Genet., 66, 609-616.

WANG, Y., FARR, C. L. AND KAGUNI, L. S. 1997. Accessory subunit of mitochondrial DNA polymerase from Drosophila embryos. J. Biol. Chem., 272, 13640-13646. 